
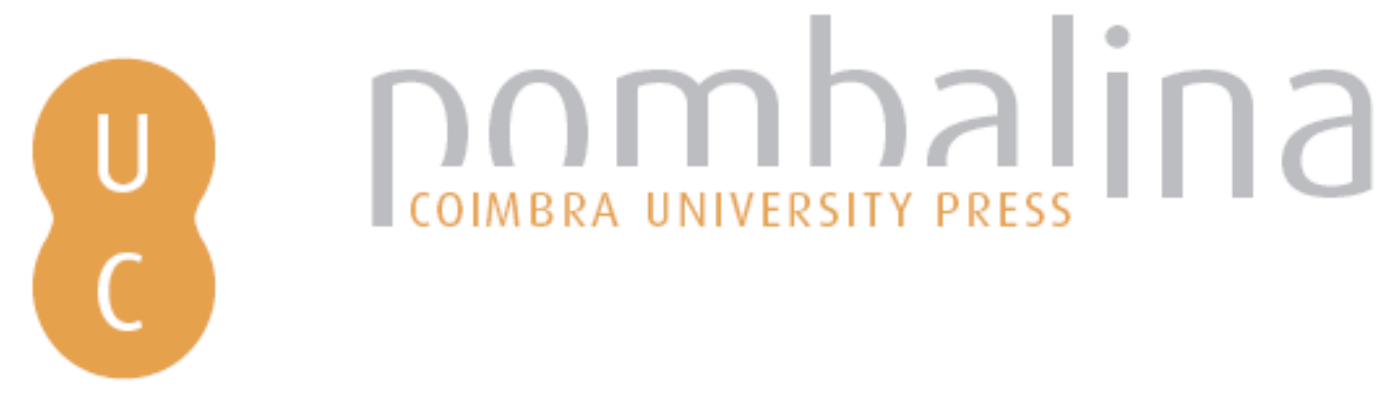

Momvs Sev de Homine: artifícios e desvios da exegese, ou das errâncias da história

Autor(es): $\quad$ Furlan, Francesco

Publicado por: Imprensa da Universidade de Coimbra

URL

persistente: URI:http://hdl.handle.net/10316.2/36664

DOI: $\quad$ DOI:http://dx.doi.org/10.14195/978-989-26-1015-3_2

Accessed : $\quad$ 26-Apr-2023 11:00:27

A navegação consulta e descarregamento dos títulos inseridos nas Bibliotecas Digitais UC Digitalis, UC Pombalina e UC Impactum, pressupõem a aceitação plena e sem reservas dos Termos e Condições de Uso destas Bibliotecas Digitais, disponíveis em https://digitalis.uc.pt/pt-pt/termos.

Conforme exposto nos referidos Termos e Condições de Uso, o descarregamento de títulos de acesso restrito requer uma licença válida de autorização devendo o utilizador aceder ao(s) documento(s) a partir de um endereço de IP da instituição detentora da supramencionada licença.

Ao utilizador é apenas permitido o descarregamento para uso pessoal, pelo que o emprego do(s) título(s) descarregado(s) para outro fim, designadamente comercial, carece de autorização do respetivo autor ou editor da obra.

Na medida em que todas as obras da UC Digitalis se encontram protegidas pelo Código do Direito de Autor e Direitos Conexos e demais legislação aplicável, toda a cópia, parcial ou total, deste documento, nos casos em que é legalmente admitida, deverá conter ou fazer-se acompanhar por este aviso.

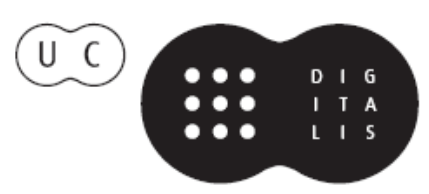


IMPRENSA DA

UNIVERSIDADE

DE COIMBRA

COIMBRA

UNIVERSITY

PRESS

\section{NA GÉNESE DAS RACIONALIDADES MODERNAS II}

Em torno de Alberti e do Humanismo

MÁRIO KRÜGER et alii

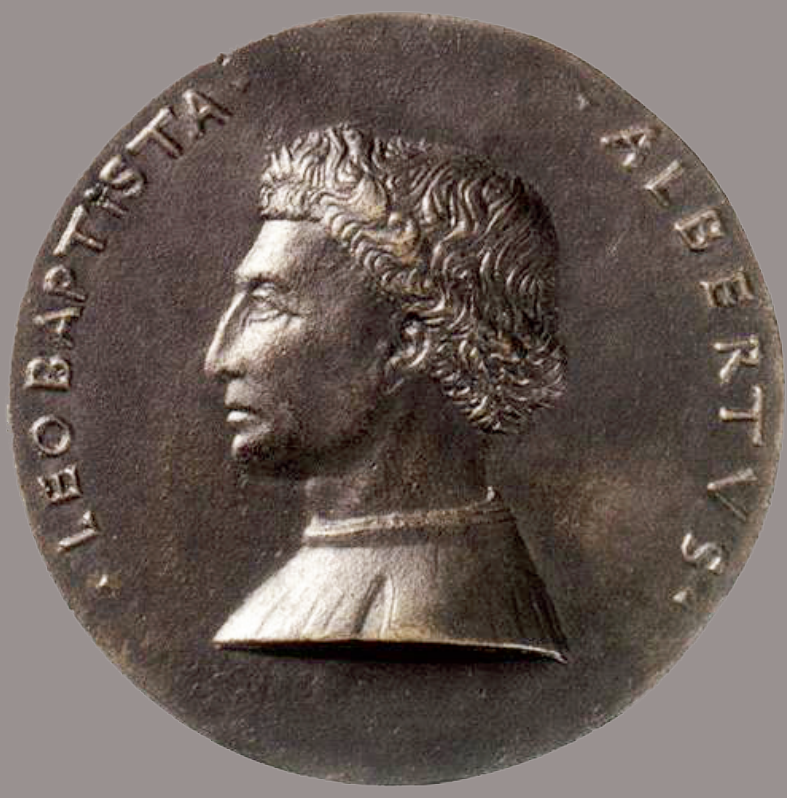




\title{
MOMVS SEV DE HOMINE: ARTIFICIOS E DESVIOS DA EXEGESE, OU DAS ERRÂNCIAS DA HISTÓRIA
}

\author{
Francesco Furlan
}

\section{Resumo}

Ainda que de forma intermitente, e por vezes distraída e de modo geral sempre parcial, dois dos seis testemunhos conservados do Momus, os mss. Marcianus Lat. VI 107 (=2851) e Parisinus Lat. 6702 (olim 6307) foram longamente e minuciosamente corrigidos por Alberti. Todavia, alguns erros, unanimemente atestados pela tradição e que só podem ser atribuídos ao próprio autor, assim como a ausência de qualquer indicação de título nos manuscritos conhecidos capaz de fazer referência à autoria de Alberti, demonstram claramente que este grande romance sui generis, considerado geralmente como a grande obra prima de seus lusi, nunca foi publicado em vida e permitem até mesmo afirmar que o título De principe da primeira edição da obra (Roma, É. Guillery, 1520), justaposto em seguida por C. Bartoli ao seu único título plausível na versão italiana que este último publicou em 1568 (Momo, overo Del principe), e retomado inclusive em suas edições e traduções em italiano, alemão, francês, espanhol...do fim do século XX, não é mais do que um título apócrifo ou, em alguns casos, um subtítulo muito inverossímil assim como uma sugestão ao mesmo tempo errônea e desconcertante do ponto de vista exegético. O Momus, com efeito, não trata de outro assunto a não ser do de Homine, isto é, dos "ineptiae", destes "homunculi" e "mulierculae" aos quais homens 
e mulheres se reduzem frequentemente e espontaneamente, dos distúrbios que assim provocam e que os deuses que criaram para si têm tendência a reiterar pela insignificância de suas ações ou opiniões; ele só evoca o príncipe como uma das numerosas máscaras às quais os humanos desde sempre se comprazem em recorrer. Leo Baptista Alberti (1404-1472); Momus; Humanismo; Renascimento Literatura neolatina.

\section{Résumé}

Deux des six témoins conservés du Momus, les mss. Marcianus Lat. VI 107 (= 2851) et Parisinus Lat. 6702 (olim 6307), ont été longuement et minutieusement corrigés par Alberti, bien que de façon intermittente et parfois distraite, et quoi qu'il en soit par endroits seulement. Quelques fautes unanimement attestées par la tradition et que l'on ne saurait attribuer qu'à l'auteur lui-même, ainsi que l'absence sur les mss. connus de toute indication de titre susceptible de remonter à Alberti, montrent toutefois clairement que ce grand roman sui generis que l'on regarde généralement comme le chef-d'œuvre de ses lusi, n'a jamais été publié du vivant de celui-ci, et permettent en même temps d'affirmer que le titre De principe de la première édition de l'ouvrage (Rome, É. Guillery, 1520), par la suite juxtaposé à son seul titre plausible par C. Bartoli, dans la version italienne que ce dernier en publia en 1568 (Momo, overo Del principe), et repris jusqu'à ses éditions et à ses traductions en italien, allemand, français, espagnol... de la fin du $\mathrm{XX}^{\mathrm{e}}$ siècle, n'est qu'un titre apocryphe ou, selon les cas, un sous-titre bien improbable ainsi qu'une suggestion à la fois erronée et déroutante sur le plan exégétique. Le Momus ne traite en effet vraiment que de Homine, i.e. des "ineptiae" de ces "homunculi" et "mulierculae" auxquels hommes et femmes se réduisent bien volontiers, des troubles causés par eux et que les dieux eux-mêmes qu'ils se sont donnés renouvellent par l'insignifiance de leurs actions ou avis, et n'évoque le prince que comme l'un des nombreux masques que les humains aiment à porter depuis toujours. 
Leo Baptista Alberti (1404-1472); Momus; Humanisme; Littérature Renaissance Néo-latine

\section{Abstract}

Two of the six surviving witnesses of Momus, mss. Marcianus Lat. VI 107 (= 2851) and Parisinus Lat. 6702 (olim 6307), were corrected by Alberti carefully and attentively, though these corrections were not applied consistently or indeed at a single time; in other words, one part of the text was corrected and another part not. The existence of some errors which are shared by the whole tradition, and which very probably come from Alberti himself, and the absence in the known mss. of a title which can be attributed to Alberti, show nevertheless clearly that this great, anomalous novel, which is the indisputable master-piece of all his lusi, was never published in Alberti's lifetime. And these facts furthermore make it possible to affirm that the title, De principe, which is present in the first edition of the work (Rome, É. Guillery, 1520) and which was later placed by $\mathrm{C}$. Bartoli alongside the only plausible title in the Italian version which the latter published in 1568 (Momo, overo Del principe), and repeated up to the editions and Italian, German, French and Spanish translations even up to the end of the $\mathrm{XX}^{\text {th }}$ century, is nothing other than an apocryphal title and, depending on the case, an extremely improbable subtitle, but one which is nevertheless an erroneous suggestion and which in the exegetical sense leads in the wrong direction. Momus is in fact openly and only de Homine, and its subjects are: the "ineptiae", or rather the state of "homunculus" and "muliercula" to which men and women often, willingly reduce themselves; and the disorder which they cause, and which the gods which they have given themselves prolong, by the insignificance of their actions or deeds. Momus only invokes the Prince in as much as it is one of the many masks which humans have always been delighted to wear.

Leo Baptista Alberti (1404-1472); Momus; Humanism; Renaissance Neo-Latin Literature. 
Momus, um dos grandes textos fundadores de Alberti e obra prima indiscutível de seus lusi, cuja edição semicrítica organizei, no passado, com Paolo d'Alessandro (publicada em sua versão espanhola em 2006 e em versão italiana em 2007, pela Mondadori), ${ }^{24}$ e cuja primeira edição crítica aparece agora pela editora Belles Lettres, ${ }^{25}$ o Momus, como eu dizia, nunca chegou a ser publicado em vida de seu autor - Alberti jamais chegou a publicá-lo.

A afirmação não deixará, sem dúvida, de surpreender, especialmente quando se tem algum conhecimento da tradição exegética recente do Momus, dentro da qual, essa informação, sob inúmeros aspetos, primordial para a real compreensão da obra, nunca é imaginada, ainda menos evocada, mesmo que de forma hipotética. Contudo, é o que se depreende claramente do estudo cuidadoso da tradição do texto deste romance que, não somente conserva alguns erros claramente atribuídos ao seu autor, atestados por todos os testemunhos conservados, tanto manuscritos como impressos, mas se destaca igualmente por uma ausência radical - e à primeira vista surpreendente ou inexplicável - de qualquer indicação de título capaz de fazer referência a Alberti nos manuscritos conhecidos, dos quais dois foram longamente (ainda de forma intermitente e parcial) revistos e corrigidos pelo próprio Alberti: o manuscrito Marcianus Lat. VI 107 (=2851), que traz ao menos duzentos e cinquenta intervenções autográficas do autor, e o manuscrito Parisinus Lat. 6702 (olim 6307) que, por sua vez, reúne um número ainda maior de intervenções de

${ }^{24}$ Cf. LeON BATtista Alberti, Momo [Momus], Texto crítico y Nota al texto de Paolo d'Alessandro y Francesco Furlan, traducidos por Alejandro Coroleu: Introducción y Nota Bibliográfica de Francesco Furlan, Notas por Mario Martelli, traducidas por María José Barranquero Cortés: Volumen al cuidado de Francesco Furlan, Milán, S.B.E., 2006; ID., Momo [Momus], Testo critico e Nota al testo di Paolo d'Alessandro \& Francesco Furlan, Introduzione e Nota bibliografica di Francesco Furlan, Traduzione del testo latino, note e Posfazione di Mario Martelli, Volume a cura di Francesco Furlan, Milano, Mondadori, 2007.

25 Cf. Leonis Baptistae Alberti Momus, Ediderunt Paolo d'Alessandro \& Francesco Furlan, em LEON BATTISTA ALBERTI, Momus, Édition critique, Notice et Commentaire philologiques par Paolo d'Alessandro \& Francesco Furlan, Traduction du latin par Claude Laurens, Notes de Claude Laurens \& Mario Martelli, Introduction de Francesco Furlan, Paris, Les Belles Lettres (= ID., Opera omnia / Euvres complètes, Publiées sous le patronage de la Société Internationale Leon Battista Alberti et de l'Istituto Italiano per gli Studi Filosofici par Francesco Furlan, SÉRIE LATINE: IX • 18), no prelo. 
Alberti, por volta de trezentas no total. Quanto aos erros unanimemente atestados pela tradição, sobre os quais acabo de afirmar que não podem pertencer à outra pessoa senão ao próprio Alberti, é importante frisar que se trata, em sua grande maioria, de inversões de nome de personagens (Polyfagus no lugar de Peniplusius, em IV 71, ou Enops para Gelastus, em IV 83, por exemplo) ou de erros pela inversão de sentido (como em I 50, servituti ao invés de libertati, 'à escravidão' no lugar de 'à liberdade'): os casos deste tipo, embora seguramente não sejam muito numerosos, - chegando dificilmente a doze - provam contudo claramente que o autor nunca releu seu texto, por assim dizer, de forma contínua, de modo a elevá-lo ao nível de coerência interna que precede em geral a publicação de escritos, sejam eles quais forem.

Convém neste quesito lembrar, ou especificar, que um número não insignificante de intervenções autográficas (correções, acréscimos ou supressões, transposições, etc.) provadas pelos dois manuscritos citados acima, Marcianus $(=M)$ e Parisinus $(=P)$, revelam-se contraditórias entre si ou caminham em direções diferentes, algo distantes, parecendo, além disso, terem sido talvez ditadas, em determinados momentos, por uma preocupação ou impressão momentânea, por uma leitura rápida de um só trecho que não permite ao autor reconstituir as razões ou o sentido de conjunto, que lhe faz esquecer, em suma, o contexto, induzindo-o, por conseguinte, a correções indevidas, pouco apropriadas ou refutadas em um segundo momento por outras intervenções ou correções autográficas que ele introduz em um manuscrito diferente. Sim, porque esse trabalho de revisão às vezes minuciosa, mas sempre parcial ou pontual, realizada, como dissemos, com intermitências, isto é, em tempos diferentes e em várias etapas, Alberti o fez sobre três codices distintos, dos quais dois foram conservados: os manuscritos $M$ e $P$, Marcianus e Parisiensis, já citados, e um perdido, a saber, o arquétipo de toda a tradição $(=\mathrm{X})$, e portanto de todos os testemunhos (manuscritos e impressos) que chegaram ate nós: o modelo ou antígrafo, em suma, dos copistas de $M$ e de $P$ - os próprios codices veneziano e parisiense - que foi também o manuscrito do qual Giacomo Mazzocchi lançou mão em 1520 para imprimir em Roma sua edição do Momus $(=M z)$ - saída do prelo, muito provavelmente, entre 
no mínimo alguns dias e no máximo algumas semanas após a edição, igualmente romana e também datada de 1520, de Étienne Guillery alias Stephanus Guileretus $(=G l)$, com a qual ela tradicionalmente compartilha a qualificação, ou até mesmo o "título" de editio princeps... ${ }^{26}$

Com efeito, tradicionalmente considera-se que não existe uma, mas duas editiones principes do Momus, o que é sem dúvida um pouco paradoxal embora isso decorra da impossibilidade, já tão propalada, de se estabelecer sua respectiva cronologia. Todavia, tendo em vista o estudo de texto que pude concluir, nesses últimos anos, com P. d'Alessandro sobre uma e outra, mostrando que G. Mazzochi muito provavelmente retomou várias lições da edição Guillery no fólio dos Corrigenda que ele insere no fim da sua edição $\left(=M z^{2}\right)$, podemos hoje em dia empregar definições mais precisas e mais apropriadas e, portanto, reservar a denominação de editio princeps unicamente à edição Guillery. Esta denominação lhe é tanto mais salutar que se trata seguramente de seu único título de glória e o único interesse que é capaz de despertar aos nossos olhos, como o veremos dentro de um instante.

Por conseguinte, ainda que a edição de Mazzochi não seja verdadeiramente a primeira edição impressa do Momus, o fato é que ela constitui um testemunho de primeira importância, especialmente porque retoma ou reflete a situação final do texto do arquétipo - situação final, portanto, das correções ou acréscimos e eliminações de Alberti sobre esse manuscrito perdido. Em virtude dessa particularidade, seu depoimento prova ser insubstituível e, mesmo que se tenha de levar em conta certa "normalização" linguística ou estilística do texto, atribuível ao próprio editor Mazocchi (mais do que a Alberti), fica claro que $\mathbf{M z}$ deve ser estudado de forma aprofundada e seriamente considerado em sua íntegra, assim como devem sê-lo $M$ e $P$, ou seja, os manuscritos veneziano e parisiense que trazem até nós numerosas intervenções de próprio punho do autor.

26 LeO BAPTISTA De Albertis FlorentinVs, De principe, Romae, apud Stephanum Guileretum [i.e. Étienne Guillery], MDXX; et Leonis Baptistae Alberti florentini Momus, Romae, ex AEd. Iacobi Mazzocchi, MDXX. 
Ora, sendo esse um dos pontos sobre os quais desejo ater-me aqui, Momus, e simplesmente Momus, é o título que nossa obra leva em $M z$, e somente em $M z$; é destarte o único título que, ainda que tenha sido eventualmente atribuído por G. Mazzocchi a este extraordinário romance de Alberti, oferece a possibilidade de remontar a seu autor - o único título que goza, por assim dizer, de um fundamento filológico e ao mesmo tempo de uma pertinência evidente e indiscutível, nosso livro sendo antes de qualquer coisa, ou melhor, em qualquer circunstância, e antes de qualquer outra eventual consideração, o "romance de Momus", incontestavelmente, seu autor principal... seu grande herói.

Observemos também que é esse mesmo título, Momus, e simplesmente Momus, que atesta, em espanhol, a mais antiga versão em volgare de nosso romance; trata-se da tradução espanhola feita por Augustin de Almazán, publicada em Alcalá de Henares em 1553, a qual recebeu precisamente o título de $E l M o m o,{ }^{27}$ e cujo texto leva a crer que foi estabelecida sobre a base - não de $M z$, como já foi afirmado, ${ }^{28}$ mas - de um manuscrito que nos é desconhecido, indo buscar sua origem, sem dúvida, no pequeno círculo de jovens ou de amigos muito jovens, de alunos, por assim dizer, de Alberti, que depois de sua morte, no fim do século XV e início do século XVI, em Florença ou na Toscana como em

27 Cf. El Momo: La moral y muy graciosa historia del Momo, compuesta en latín por el docto varon Leon Baptista Alberto Florentín, Transladada en Castellano por Augustín de Almaçán [...], Madrid, Iuan de Medina, MDLIII necnon Alcalá de Henares, Joan de mey Flandro, 1553.

28 Cf. MARIA JOSÉ VEGA, Traducción y reescritura de L.B. Alberti: El Momo castellano de Agustín de Almazán, em "Esperienze letterarie", XXIII, 1998, pp. 13-41: 15, n. 2 - que afirma ter MARIO DAMONTE (Testimonianze della fortuna di L.B. Alberti in Spagna: Una traduzione cinquecentesca del Momus in ambiente erasmista, em "Atti della Accademia ligure di Scienze e Lettere", s. V, XXXI, 1974 [sed 1975], pp. 257-283 - retomado em ID., Tra Spagna e Liguria, Genova, Accademia Ligure di Scienze e Lettere, 1996, pp. 186-208) "demostrado que la traducción castellana de Almazán se basó en el texto de la edición de Mazzocchi”, i.e. de $M z$, ao passo que Damonte nunca chegou a se interessar por esta questão; com efeito, ele escreve sem mais detalhes em seu último estudo sobre o tema: "La versione [d'Augustín de Almazán] fu condotta su un manoscritto oppure su una delle due edizioni del 1520" (ID., Attualità del Momus nella Spagna del pieno Cinquecento: La traduzione di Augustín de Almazán, em Leon Battista Alberti: Actes du Congrès international de Paris (Sorbonne-Institut de France-Institut culturel Italien-Collège de France, 10-15 avril 1995) tenu sous la direction de F. Furlan, P. Laurens, S. Matton, Édités par Francesco Furlan, Paris, J. Vrin \& Torino, Aragno, 2000, pp. 975-992: 976). 
Roma ou alhures, em Veneza, Pádua, Ferrara..., cultivavam ativamente sua memória e difundiam sua obra: ${ }^{29}$ é muito provavelmente neste contexto que se insere a edição de Girolano Massaini de 1499, ou 1500 ou 1501, dum volume de Opera latinos de Alberti que deveria ter sido o primeiro de uma série compreendendo especialmente o Momus e as Interconales mas que, atingido pelos raios da censura florentina ou, melhor dizendo, pelo ódio voltado em Florença ao próprio nome de Alberti, permaneceu, infelizmente, sendo o único. 30

Enfim, Momus, sem mais, é também e além disso, o título da mais antiga versão alemã, aquela que Georg Meissner publicou em Viena, hoje Áustria, em 1790.31

Por outro lado, o pseudo-título ou falso subtítulo De príncipe que a edição italiana contemporânea, desde a edição Martini (1942) até a edição Consolo (1986) apresentou como concorrente, chegando a transformá-lo em verdadeiro título da obra no espírito do leitor não filólogo e, não raro, no espírito do leitor comum, imitada logo em seguida pelos autores das traduções alemã, francesa e espanhola... impressas recentemente; este pseudo-título De principe foi de início uma criação de Étienne Guillery que, não achando em suas fontes - surpreenderia

29 Cf. PAOLO D'ALESSANDRO \& FRANCESCO FURLAN, Commentaire philologique et linguistique, em L.B. AlBerTI, Momus, ed. d'Alessandro \& Furlan cit., IV 71, ad voc. "Polyfagi".

30 Cf. Hieronymus Massainus Roberto Puccio S(alutem), em Leonis Baptistae Alberti Opera, [Hieronymo Massaino curante], s.l.n.d. [sed Florentiae, Per Bartholomeum de Libris, MCDXCIX?], fos a $1 v$-4r; FRANCESCO FURLAN \& SYLVAIN MATTON, Baptistae Alberti Simiae et de nonnullis eiusdem Baptistae apologis qui nondum in vulgus prodiere: Autour des intercenales inconnues de Leon Battista Alberti, em "Bibliothèque d'Humanisme et Renaissance", LV, 1993, pp. 125-135; FRANCESCO FURLAN, Studia albertiana: Lectures et lecteurs de L.B. Alberti, Paris, J. Vrin \& Torino, Aragno, 2003, pp. 157-172 e 195-206 especif.; LUCA D'ASCIA \& STEFAno SimonCIni, Momo a Roma: Girolamo Massaini fra l'Alberti ed Erasmo, em "Albertiana", III, 2000, pp. 83-103; FRANCESCO FURLAN, "Io uomo ingegnosissimo trovai nuove e non prima scritte amicizie" (De familia, IV 1369-1370): Ritorno sul libro de Amicitia, em Leon Battista Alberti (1404-1472) fra scienze e lettere, Atti del Convegno organizzato in collaborazione con la Société Internationale Leon Battista Alberti (Parigi) e l'Istituto Italiano per gli Studi Filosofici (Napoli): Genova, Palazzo ducale, 19-20 novembre 2004, A cura di Alberto Beniscelli e Francesco Furlan, Genova, Accademia Ligure di Scienze e Lettere, 2005, pp. 327-340; PAOLO D’ALESSANDRO \& DAVID MARSH, Girolamo Massaini trascrittore dell' Alberti, em "Albertiana”, XI-XII, 2008-2009 [= DAVID MARSH, Studies on Alberti and Petrarch, Farnham, Ashgate, 2012, n XVII], pp. 260-266.

31 Cf. Momus des LEO BAPTISTA AlBeRTi, [Herausgegeben von A. Georg Meissner,] Gedruckt bey Ignaz Alberti, Wien, Fr. Jak. Kaiserer, 1790. 
se fosse o contrário! - nenhuma indicação de título, decidiu criar um do zero para sua editio princeps de $1520 .{ }^{32}$

Assim, ele introduzia na tradição do Momus uma indicação claramente equivocada ou falsa e ao mesmo tempo uma interpretação desconcertante e perfeitamente inaceitável, mas que gozou de enorme aceitação até os dias de hoje - uma indicação e interpretação fantasiosas, tão pouco exatas ou pertinentes aos olhos de todo bom exegeta quanto é superficial ou simplesmente inútil aos olhos de um filólogo, o texto de sua edição. De um ponto de vista ecdótico, este último não é mais do que um descriptus de $P$, uma cópia portanto do codex Parisiensis citado, e como tal, completamente inútil, devendo ser descartado ou eliminado prontamente e resolutamente em vista do estabelecimento do texto crítico do Momus.

Por volta de quarenta anos mais tarde, a inventividade igualmente "criadora" de Cosimo Bartoli, viria juntar-se à duvidosa criação de Étienne Guillery, à sua extravagante invenção e completar sua obra tão falaz quanto detestável. É, com efeito, a C. Bartoli e aos seus Opuscoli morali di Leon Batista Alberti, impressos em Veneza em 1568, que pode ser atribuída a justaposição de títulos, extremamente distantes para não dizer divergentes e até contraditórios entre eles, das duas edições romanas de 1520: de um lado, Momus, e do outro, De principe. Por isso, o título Momo, ouero Del príncipe foi o escolhido por Bartoli ${ }^{33}$ - ponto de partida de todas as traduções que seguiram: Momus seu De principe, em latim; Momus o Del principe, em italiano; Momus oder Vom Fürsten, em alemão; Momus ou Le prince, em francês; Momus o Del príncipe, em espanhol...

Por isso, não parece inútil assinalar rapidamente os estragos provocados à ideia que desenvolvemos pela empresa de vulgarização da obra de

32 Para isso, teria ele buscado inspiração na sugestão, de resto, tão sintética quanto genérica ou vaga, do Proømium 7 ? É possível dar fé a esta hipótese sem muita dificuldade. A verdade é que desde os primeiros parágrafos do livro $\mathrm{I}^{\circ}$, esta sugestão não só se revela completamente ultrapassada como chega a ser refutada.

33 Momo, ouero del Principe, em Opuscoli morali di Leon Batista Alberti gentil'buomo firentino: Ne' quali si contengono molti ammaestramenti, necessarij al viuer de l'Huomo, cosí posto in dignità, come priuato, Tradotti, \& parte corretti da M. Cosimo Bartoli, Venetia, Francesco Franceschi, 1568, pp. aIII-VI et 1-120. 
Alberti, à qual Bartoli se dedicou na metade do século XVI. De resto, se refletirmos sobre os obstáculos que sua tradução do título De re aedificatoria por Architettura assim como sua "aggiunta de disegni", isto é, a adição de desenhos e figuras de sua própria lavra, ${ }^{34}$ atendo-nos apenas a estes dois aspetos, trouxeram ao caminho da verdadeira compreensão desta obra seminal ou fundadora, devemos concluir - penso eu - que Messer Cosimo Bartoli contribuiu menos para popularizar o nome de Alberti do que para falsear sua obra ou para distorcer seu sentido...

Mas o que devemos sobretudo guardar em memória atualmente é o sucesso quase sem limites do qual gozou a sugestão culposa e falsa de Guillery, relançada por Bartoli, não somente junto aos editores do texto do Momus e de seus tradutores contemporâneos, mas também junto aos seus intérpretes ou críticos e comentadores, ou ainda junto aos seus simples leitores de ontem e dantes d'ontem - sucesso que, muito provavelmente, pela inércia das coisas humanas, de desfrutar ainda hoje, ou amanhã, junto àqueles entre os quais persistiria a ignorância dos dados e dos fatos precisos, os quais apenas relembrei aqui rapidamente.

Outrossim, é necessário salientar o obstáculo que esta falsa sugestão levantou e ainda levanta no caminho de uma verdadeira e inteira compreensão do Momus. Porque não há dúvida de que, caso o propósito fosse acrescentar ao título deste romance uma indicação qualquer, como subtítulo, ou melhor, como simples explicação, não se poderia apelar para outra opção que não fosse à da precisão de Homine: Momus seu De homine, como o fiz, diga-se de passagem, para o título da presente contribuição.

Pois é somente do homem ou do gênero humano, do homem e da mulher da mesma forma, que Alberti nos fala nesta obra. Somente de sua depravação e de suas misérias, de sua estupidez, sua incoerência e sua loucura, de seu absurdo, irracionalidade, loucura, como do excesso de sua miopia - em suma, de sua incapacidade intrínseca em elevar-se e atingir a posição de "mortale iddio felice", vislumbrada e até mesmo celebrada

34 Cf. L'architettura di Leonbatista Alberti, Tradotta in lingua fiorentina da Cosimo Bartoli gentil'huomo \& accademico fiorentino: Con la aggiunta de disegni, Firenze, Lorenzo Torrentino, MDL. 
alhures em sua obra. ${ }^{35}$ De tal modo que, se lhe ocorre concentrar-se sobre o príncipe - haveria algo mais previsível e, em última instância, mais natural? - se lhe vem à mente pintar, com os traços de Júpiter, um príncipe que ninguém desejaria ter como amigo, como parente ou simples conhecido, ele só o faz, incontestavelmente, porque existe e sempre existiram príncipes, entre os homens, isto é, indivíduos cuja máscara a eles atribuída pelo destino, é de fato a máscara do príncipe.

Decididamente, pode-se aventar que o príncipe só é representado pelo Momus como hominis figura, ou persona: é na qualidade de figura humana e ao mesmo tempo como uma das inúmeras máscaras que os homens se comprazem em usar que Júpiter, príncipe entre os príncipes, sobe ao palco do Momus.

É a razão pela qual pode parecer incongruente e até estranho, e ao mesmo tempo deplorável, que se tenha buscado encontrar aproximações improváveis entre nosso romance propriamente inclassificável, porque desprovido de modelos reais e não admitindo, em esfera alguma, sua eventual inscrição em um gênero literário ou filosófico preciso, e os textos de Principe que os renascentistas, prolongando ao seu modo a tradição dos Specula medievais, acumularam tanto no Quattrocento quanto no Cinquecento. 36

35 Cf. LEON BATTISTA ALBERTI, I libri della famiglia, A cura di Ruggiero Romano e Alberto Tenenti, Nuova edizione a cura di Francesco Furlan, Torino, Einaudi, 1994 \& $2002^{2}$, II 1784.

36 É o que se empenha em fazer, entre muitos outros, M.J. VEGA, Traducción y reescritura de L.B. Alberti..., cit., especialmente pp. 25 ss. e 32 ss. - cujo estudo se desenvolve, porém, a partir das necessidades da análise "de la actividad interpretativa" de Augustín de Almazán (ibid., p. 15) e tem o mérito de enquadrar esse exercício de forma crítica, especificando claramente que "Si se acepta que el Momo es un libro de principe, debe concederse también que es notablemente excéntrico: carece de destinatario conocido y no se presenta como tratado, sino como ficción gentílica; no es ciceroniano, sino lucianesco; no trata el retrato moral del optimus princeps, sino de dioses intrigantes, fracasados o matreros; los exempla, o los que pudieran considerarse como tales, son notablemente subversivos; carece de elogios e incluso de reflexiones sobre la bontad de la vida civil y activa, y el único oficio del hombre que sale bien parado es el del mendicante, pícaro y vagabundo. Tampoco acude ni se fundamenta en la tradición moralista: antes bien, contiene una sátira de la vida y costumbres de los filósofos morales [...]" (ibid., p. 33 s.). 
Romance pseudomitológico, em muitos aspetos impenetrável, impregnado de humor cáustico, cheio de alusões indecifráveis ao mundo contemporâneo e, mais ainda, de referências aos universais humanos, o Momus é, sem dúvida alguma, o lusus mais cativante de Alberti, uma das três grandes formas de escrita e de investigação - junto com o tratado e o diálogo - que o humanista cultivou e nas quais brilhou. ${ }^{37}$ É também, incontestavelmente, a obra prima da prosa humanista do século XV e um dos pontos culminantes da literatura humorística de todos os tempos em língua latina.

Considerá-lo como uma banal alegoria política, necessariamente repisada, seria seguramente empobrecê-lo em grande parte, não obstante, seria ainda mais simplista e certamente totalmente inapropriado, continuar a lê-lo sob um ângulo falsamente documentário e pseudo-histórico ou pseudo-autobiográfico, propondo, na esteira de Girolamo Mancini, identificações improváveis e inconsistentes entre tal e tal personagem contemporâneo e uma ou outra figura do romance. Quando se conhece Alberti e seu lusus, estas identificações, em grande parte falaciosas ou especiosas, aparecem ao primeiro olhar e são, não somente fundadas inevitavelmente sobre um "paradigma indiciário", impressionista e obscuro - não raro semeadas de argúcias tautológicas - mas também são impregnadas de uma espécie de diletantismo ingênuo e totalizante que as conclusões discordantes daqueles que as propõem só fazem denunciar. ${ }^{38}$ De resto, como poderíamos seriamente

37 Cf. FRANCESCo Furlan, Per un ritratto dell' Alberti, em "Albertiana”, XIV, 2011, pp. 43-53: 50-52 especif..

38 Podemos citar como exemplo a identificação proposta por GIROLAMO MANCINI de Alberti com Gelasto (Vita di Leon Battista Alberti, Seconda edizione completamente rinnovata con figure illustrative, Firenze, Carnesecchi, 1911 [= Roma, Bardi, 1967 \& 19712], p. 264) e retomada, entre outros, por GIOVANNI PONTE (Leon Battista Alberti umanista e scrittore, Genova, Tilgher, 1981 \& $1991^{2}$, p. 93) e por ROBERTO CARDINI (Alberti o della nascita dell'umorismo moderno: I, em "Schede umanistiche", I, 1993, pp. 31-85: 64), quando RINALDO RINALDI ("Melancholia christiana": Studi sulle fonti di Leon Battista Alberti, Firenze, Olschki, MMII, p. 135), para quem "le due facce dell'intellettuale Alberti" seriam ao contrário Hércules e Momus, vê em Gelasto um "scalcinatissimo e ridicolo tipo di filosofo aristotelico". Este mesmo autor, cuja interpretação do Momus é às vezes tão surpreendente quanto certas passagens do romance de Alberti, considera, no mais, poder estender este tipo de interpretação tanto ao preâmbulo da obra do que ao seu dedicatório (cf. ibid., pp. 118 ss.) - que ele se compraz em definir como "segreto" mas 
entrever no Momus, ou na comédia de quiproquós da qual ele fornece um cenário dos mais brilhantes, um roman à clef? Que interesse pode haver na identificação a priori mistificadora em todo teatro de máscaras bem pensado, na identificação, dizia eu, do autor, ora como Momus, seu herói proteiforme, ou como Júpiter, ora como o filósofo Gelasto, como Hércules ou como Charon? No fundo, que importância haveria em provar a pertinência da identificação de um Francesco Filelfo ou de um Niccolò Niccoli com Momus? Ou de reconhecer-se a identidade de tal ou tal papa ou do cardinal Vitelleschi ou de seu sucessor, o cardinal Scarampi, em um Júpiter apresentado exclusivamente como "caelorum rex" e "deorum pater", ou ainda como "rerum conditor"? $\mathrm{Na}$ realidade, bem pouca importância haveria. ${ }^{39}$ Assim, mesmo rejeitando firmemente toda hipótese de frustração diante da impossibilidade de descobrir a pretendida alegoria que estaria estruturando toda a obra, podemos compartilhar sem muita reticência, uma leitura que desencerra no Momus e em suas incessantes invenções narrativas a firme determinação como foi a de Alberti, para "impedire puntigliosamente ogni identificazione di persone e fatti". 40

Com efeito, a este respeito, convém ater-se simplesmente à declaração liminar do autor a respeito de sua originalidade, por sinal evidente, e da nova forma de escrita, verdadeiramente filosófica inerente a uma obra que, aliando com proveito a "dignitas" do sujeito e a "gravitas" da expressão ao riso e aos chistes (risus et ioci), distrai agradavelmente o leitor:

\footnotetext{
que, na realidade, é somente imaterial e puramente genérico, assim como radicalmente impossível de ser identificado, em razão da não publicação do Momus na realidade histórica do Quattrocento.

39 Um rápido resumo das identificações propostas pode ser encontrado na Introduction à LEON BATTISTA AlBerTI, Momus, English translation by Sarah Knight, Latin text edited by Virginia Brown and Sarah Knight, Cambridge (Mass.) \& London, The Harvard University Press, 2003, pp. VII-XXV: XXII s.

40 NANNi BALESTRIni, Presentazione, em LeOn BATTISTA AlBerti, Momo o Del principe, Edizione critica e traduzione a cura di Rino Consolo, Introduzione di Antonio Di Grado, Presentazione di Nanni Balestrini, [Note di Rino Consolo e Antonio Di Grado,] Genova, Costa \& Nolan, 1986, pp. V-X: VII.
} 
non me [...] fugit quam difficillimum ac prope impossibile sit aliquid adducere in medium quod ipsum non a plerisque ex tam infinito scriptorum numero tractatum deprehensumque extiterit. Vetus proverbium: nihil dictum quin prius dictum. Quare sic statuo, fore ut ex raro hominum genere putandus sit, quisquis ille fuerit, qui res novas, inauditas et praeter omnium opinionem et spem in medium attulerit. Proximus huic erit is qui cognitas et communes fortassis res novo quodam et insperato scribendi genere tractarit. Itaque sic deputo: nam si dabitur quispiam olim qui cum legentes ad frugem vitae melioris instruat atque instituat dictorum gravitate rerumque dignitate varia et eleganti idemque una risu illectet, iocis delectet, voluptate detineat - quod apud Latinos qui adhuc fecerint nondum satis exstitere - hunc profecto inter plebeios minime censendum esse. // [...] fortassis essem assecutus ut apertius intelligeres versari me in quodam philosophandi genere minime aspernando. [...] elaboravimus ut qui nos legant rideant aliaque ex parte sentiant se versari in rerum pervestigatione atque explicatione utili et minime aspernanda. [...] Quod si senseris nostra hac scribendi comitate et festivitate maximarum rerum severitatem quasi condimento aliquo redditam esse lepidiorem et suaviorem, leges, ni fallor, maiore cum voluptate.
Estou ciente do quanto é difícil e quase impossível produzir algo que, no meio de tão numerosos autores, não tenha sido ainda tratado e escolhido por grande número d'entre eles. Um velho provérbio diz: "Nada é dito que já não o tenha sido". Eis porque considero dever o autor - seja qual for - que vier a produzir uma obra nova, única e surpreendente, ser posto em uma categoria de exceção. Logo em seguida virá aquele que tratar de tema conhecido e talvez banal, embora o faça de forma inovadora e com estilo original. Assim, em minha opinião, se existe um escritor que predispõe e prepara seus leitores a uma vida mais virtuosa pela seriedade de seus propósitos, pela dignidade, variedade e elegância dos seus argumentos e que ao mesmo tempo os diverte e os encanta - o que não encontramos até o presente nos escritores de língua latina - ele não deverá ser considerado como mais um entre seus pares. // [...] Terei talvez conseguido convencer de que meu fito era praticar uma forma de filosofia que não tem nada de desprezível. Por outro lado, fiz de tudo para que meus leitores se divertissem e se dessem conta de que participavam de uma investigação e exame, úteis e respeitáveis. [...] Se acaso tiveres a impressão de que minha jovialidade e minha verve são como um condimento destinado a tornar mais leve e mais doce a severidade dos grandes temas, você me lerá, salvo engano, com mais prazer. ${ }^{40}$

Temos de admitir que nosso romance multiforme, embora não trate do príncipe, remete claramente, "a un universo irregolare e sconvolto, ad un Olimpo travolto da frodi e discordie, ad una condizione umana di sofferenza senza speranza, a progetti tanto grandiosi quanto inconcludenti di rifare il mondo", 42 como foi escrito com muita propriedade.

É, sobretudo, o embrenhar de infinitas, imprevisíveis e inacreditáveis aventuras do herói e seu encontro com a personalidade singular, na verdade bastante inconsistente de um Júpiter - "não correspondendo em nada à ideia que se faz de uma divindade" 43 - que dão origem, ao longo do romance, a uma "comicidade crítica e paradoxal" 44 e às vezes até, em grande parte, verdadeiramente surreal.

\footnotetext{
${ }^{41}$ Cf. L. B. Alberti, Momus, ed. d'Alessandro \& Furlan cit., Pr. 4-5.

42 G. PONTE, Leon Battista Alberti umanista e scrittore, cit., p. 90.

43 Cf. Ibidem, p. 93: "che non risponde certo ad un concetto di divinità minimamente attendibile".

${ }^{44}$ R. CARDINI, Alberti o della nascita dell'umorismo moderno..., p. 32.
} 
Descido, como foi dito, do "Olimpo decaído de Luciano" 45 e descrito de maneira incisiva em I 2, através de uma enunciação feliz que põe logo de início em evidência seu temperamento original na Assembleia dos deuses:

omnium unus est Momus qui cum singulos Momus é o único que folga extraordinariamente odisse, tum et nullis non esse in odio mirum in em detestar todo mundo e em ser detestado modum gaudeat.

por todos.

Momus não é outro senão um alter ego extremista, radical ou até mesmo inflamado do autor e, por conseguinte, de qualquer um de nós - ou se preferirmos, uma projeção de nós mesmos, uma projeção brincalhona resultante do desespero, louca de lucidez assim como de amarga e dolorosa malícia.

Deus altercador da crítica e da provocação, desestabilizador e quase terrorista pelas suas incessantes fantasias subversivas; deus intratável, odiento, difamador, caluniador e demagogo, Momus é também aquele que revela muito lucidamente a verdade dos fatos e das coisas, assim como os móbeis e as intenções dos homens e dos deuses. Capaz tanto de desmascarar sem piedade que de mistificar da maneira mais grosseira e mais inesperada, ele é, por um lado, descrito sobretudo como um deus do escárnio e da dessacralização, por outro, da metamorfose, da duplicidade ou da dissimulação.

São, todavia, a ambiguidade impenetrável, a incansável polivalência e ao mesmo tempo a atividade frenética e a imaginação desregrada demonstradas por ele que estão na origem da tendência niilista e da alma anarquizante desta divindade camaleônica.

Para lançar luz sobre sua indubitável e inquietante função subversiva, é suficiente referir-se, por um lado, em I 26-31, à sua tentativa memorável (e, como se não bastasse, posta em prática na Etrúria!), de fazer cessar o culto dos deuses que o tinham exilado, propagando sua inexistência e afirmando que vida humana não é mais do que um divertimento ou um brinquedo da Natureza (ludum esse Naturae hominum vitam) e, do outro, em II 47-63,

45 Cf. ANTONIO DI GRADO, Introduzione: L'ombra del camaleonte, em L.B. ALBERTI, Momo o Del principe, ed. Consolo 1986 cit., pp. 1-18: 8 - retomado com modificações e acréscimos, sob o título L'ombra del camaleonte: Il Momus di Leon Battista Alberti, em ID., Dissimulazioni: Alberti, Bartoli, Tempio: Tre classici (e un paradigma) per il millennio a venire, Caltanissetta-Roma, Sciascia, 1997, pp. 11-41: 26: "Olimpo degradato di Luciano". 
ao seu surpreendente elogio (menos paradoxal, todavia, do que parece), dos mendigos e dos vagabundos (eorum qui quidem vulgo mendicant, quos errones noncupant), do ócio e da impassibilidade portanto, assim como dos prazeres e dos poderes associados à ausência, ou ainda, à sua recusa categórica de toda responsabilidade verdadeira. Esta esplêndida e memorável apologia é provavelmente, do ponto de vista literário, a "plus belle page" de Alberti como o afirma Robert Klein. ${ }^{46}$ Retrato realmente admirável este dos “errones", nos quais Mario Martelli mostrou com discernimento e delicadeza que era necessário ver - entre outros aspetos, claro, mas particularmente em alguns deles - os "errabondi filosofi o itineranti frati" de então, o modelo, em suma, dos membros das Ordens mendicantes: com o frade pregador dominicano, o frade menor portanto, ou o próprio franciscano esmoleiro. ${ }^{47}$

Entre as funções de Momus está asseguradamente aquela já exercida por Ésopo, o escravo da Antiguidade, destinada a encarnar-se mais tarde nos inesquecíveis clowns de Shakespeare. Esta função consiste em desmascarar as aparências, em desvelar a verdade e fazer aceitá-la pelo viés de suas histórias, de suas invenções ridículas e, além disso, não raro grotescas, ou violentas, e sempre perfeitamente "inconvenientes".

Não é portanto uma coincidência se Momus, cuja causa que defende torna-o frequentemente eloquente, se lança às vezes em uma disputa

46 Cf. ROBERT KLEIN, Le thème du fou et l'ironie humaniste, em "Archivio di Filosofia", III: Umanesimo e ermeneutica, 1963, pp. 11-25 - retomado em ID., La forme et l'intelligible: Écrits sur la Renaissance et l'art moderne, Articles et essais réunis et présentés par André Chastel, Paris, Gallimard, 1970, pp. 433-450: 448.

47 Cf. MARio MARTElLi, Minima in Momo libello adnotanda, em "Albertiana”, I, 1998, pp. 105-119 \& II, 1999, pp. 21-36: 22-31 (i.e. § VIII: "Erronum laudes") e, quanto à citação, ver p. 24. Se, ao nosso ver, não é possível duvidar de tal observação - particularmente, quando relemos os $\S \S 50-54$ do livro II, onde tal identificação salta aos olhos - convém todavia sublinhar que ela não deve ser considerada exclusiva, o que, contradizendo as observações gerais formuladas acima, seria uma negação do fato de que Alberti, também nesta ocasião, tomou o evidente cuidado de tecer uma ampla série de fios, alguns dos quais foram transmitidos à sua profissão pela tradição grega: e mais ALBERTO TENENTI, Le paradoxe chez Léon-Baptiste Alberti, em Le paradoxe au temps de la Renaissance, Directeur de la publication: M.T. Jones-Davies, Paris, Jean Touzot, 1982, pp. 169-180: 176, consultar a este respeito igualmente PHILIPPE GUÉRIN, L'éloge de l'erro dans le Momus de Leon Battista Alberti, ou d'un art sans art, em Journée d'études Otium: Antisociété et anticulture organizée [sic!] par Maria Teresa Ricci: C.É.S.R., Tours, 24 octobre 2008, s.l., Banca Dati "Nuovo Rinascimento": http://www.nuovorinascimento.org, 2009, pp. 5-21; PIERRE LAURENS, Avez-vous lu Maxime de Tyr?, em Les oeuvres latines de Leon Battista Alberti, Actes de la Journée d'études: Paris, Maison de la recherche, 4 mai 2012, em preparação; et L.B. ALBERTI, Momus, ed. d'Alessandro \& Furlan cit., II 47, n. 71. 
filosófica, tornando-se facilmente um escudo - como está dito em II 76 (cum eloquentem ipsa causa faceret, tum se dicente veritas ipsa atque ratio facile tutaretur atque defenderet) - da verdade e da própria razão. Não obstante, ele é capaz de demonstrar mais interesse pelo conhecimento do que pelos seus próprios infortúnios. É assim que em IV 72, expulso definitivamente do Olimpo dos Deuses e acorrentado a uma rocha, ele aparece claramente na (simples e a sua maneira, demasiado nobre) figura de um homem - do Homem. Podemos assim, sem dúvida alguma, intuir nele uma sensibilidade assim como necessidades e projetos tipicamente albertianos, cujas recorrências ou epifanias poderiam ser facilmente evidenciadas em toda, ou quase toda, obra do humanista.

O Momus nunca foi publicado por Alberti - isso já foi dito e destacado. Para além dos numerosos indícios semeados ao longo do texto e das verdadeiras provas filológicas que evoquei para prová-lo, é fato que surpreende, questiona. Assim, podemos ou devemos interrogar-nos a este respeito.

Digamos que isto surpreende sobretudo aqueles que ignoram ou não compreendem de fato a natureza deste romance, o sentido último desta grande obra prima que pinta com uma verdadeira profusão e quase um transbordamento - um excesso até, poderíamos dizer - de lucidez e de verve, as misérias e a pequenez do homem, destes "homunculi" - há ao menos dez ocorrências no Momus deste diminutivo muito raro e quase único, que não tem seguramente nada de afetivo -, destes 'homenzinhos desprezíveis' que, acompanhados de costume por suas "mulierculae", por suas 'mulherzinhas', só pensam em “ineptiae”, só fazem ou realizam 'lamentáveis besteiras'. Um paralelo pode ser traçado com o Defunctus da mais desenvolvida das Interconales, embora o ponto de vista adotado por Alberti, de maneira ainda mais exigente e rica, não poderia ser mais elevado à medida que reduz proporcionalmente as dimensões do homem e o possível sentido de sua presença no mundo. ${ }^{48}$

48 Cf. FRANCESCO FURLAN, La donna, la famiglia, l'amore: Tra Medioevo e Rinascimento, Firenze, Olschki, 2004, p. 49: "in larga parte sprovvista di senso, la realtà ivi [nelle 
Estamos longe, muito longe aqui de toda e qualquer fé no homem ou no ser humano; distantes, muito distantes de qualquer perspetiva humanista stricto sensu. Alberti dá a impressão de ter chegado a um estado de indiferença, ou quase, frente ao mundo humano (e divino), cuja razão de ser aparece de ora em diante ininteligível, irremediavelmente impenetrável. Se ele não terminou integralmente seu romance, se ele talvez tenha se esquecido de atribuir-lhe um título, é que pouca importância atribuía à sua publicação ou à sua divulgação - aos seus olhos importava apenas escrevê-lo, trazer a lume (não para nós, mas para si mesmo) uma leitura impiedosa do mundo e da vida que são os nossos.

Naturalmente, Alberti não tinha nada a temer, nada a perder também com a publicação do Momus: aqueles que pensam o contrário esquecem não somente os possíveis efeitos de catharsis que esta leitura comporta; na realidade, por miopia ou por pobreza de espírito, eles consideram estar diante de um verdadeiro roman à clefs ou creem poder encontrar no Momus uma sátira de costumes. Diferentemente de todos estes intérpretes, inditosamente tão pobremente dotados, Alberti soube elevar-se ao nível dos universais e sobrepujar, sem hesitações, toda contingência e toda eventual fonte material de inspiração a fim de dissolvê-las e fazer com que caíssem no esquecimento.

Alberti não tinha, portanto, nada a temer ou nada a perder caso publicasse o Momus. Mas não o fez. Ele o concebeu, escreveu, copiou ou fez copiar diversas vezes, e o corrigiu também durante um bom tempo, ainda que sempre parcialmente, trabalhando sobre três manuscritos diferentes sem nunca o publicar. Aos seus olhos - trata-se de uma evidência - isso não tinha a mínima importância ou não fazia o mínimo sentido. Pois, quando se tem do homem e dos seres humanos uma ideia como a que expõe o Momus, não se pode nem pedir-lhes algo e tampouco imaginar receber

\footnotetext{
Intercoenales e nel Momus] dipinta è dominata dal delirio umano e divino, dall'irruzione del caso, della fortuna, dell'assurdo... In questi casi spaventosamente in alto viene a trovarsi l'autore e la sua posizione è allora quella di chi giudica una realtà il cui significato dilegua: gli uomini non sono che "homunculi" e "ineptiae" i loro atti, in una deformazione che diminuisce e depaupera le cose tutte. L'assurdità dell'uomo, la sua insignificanza vanificano ogni contatto, ogni possibilità di dialogo. Il discorso albertiano si vena di misantropia e secondariamente - solo secondariamente - di misoginismo".
} 
algo deles; quando se chega ao ponto de não encontrar uma razão de ser à religião, negando até a existência de qualquer divindade, de qualquer deus, com a exceção de uma Natureza que não parece importar-se muito com os problemas humanos (nullos inveniri deos, praesertim qui hominum res curasse velint, vel tandem unum esse omnium animantium communem deum, Naturam, afirma, de fato, Momus); e quando este Júpiter "Muito bom Muito grande" (Optimus Maximus) é apontado como uma criação de nossa mente, uma criação que talvez não seja das melhores, e que se aparenta, em todo caso, a uma pura e simples impostura, a uma superstição mistificadora; quando se pode e se quer chegar até aí, é que de ora em diante renuncia-se ou que sem dúvida já renunciou-se a nada ansiar ou esperar deles.

Se, mesmo na ausência radical de qualquer expectativa e de qualquer esperança, é possível ainda criar, escrever, corrigir ou pesquisar, isto significa que a escrita, a pesquisa e o estudo, o conhecimento ou a virtude são objetivos em si e permitem não somente vencer os males da vida ou de "espurgare la erumna", segundo a expressão dos Profugia, ${ }^{49}$ mas sobretudo, fruir da felicidade mais verdadeira, mais profunda e mais durável que nos tenha sido permitido experimentar:

Se tu sarai litterato, tu conoscerai quanto sieno meno felici gl'ignoranti,

lê-se, com efeito no De familia, ${ }^{50}$ porquanto:

Non si può descrivere né stimare il piacere qual seque a chi cerca presso a' dotti le ragioni e cagioni delle cose; e vedersi per questa opera fare da ogni parte piú esculto, non è dubbio, supera tutte l'altre felicità qual possa l'omo avere in vita

diz-nos, no outono da vida, o autor de De iciarchia. ${ }^{51}$

49 LEON BATTISTA AlBerTi, Profugiorum ab aerumna libri III, em ID., Opere volgari, A cura di Cecil Grayson, vol. II: Rime e trattati morali, Bari, Laterza, 1966, pp. 105-183: 180, 11. $20 \mathrm{~s}$.

50 ID., I libri della famiglia, ed. Furlan cit., II 2040-2041.

51 ID., De iciarchia, em ID., Opere volgari, A c. di C. Grayson, vol. II, cit., pp. 185-286: 213. 